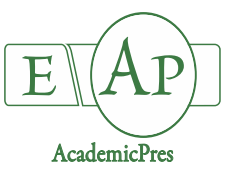

Zheng W et al. (2021)

Notulae Botanicae Horti Agrobotanici Cluj-Napoca

Volume 49, Issue 1, Article number 12191

DOI: $10.15835 /$ nbha49112191

Research Article

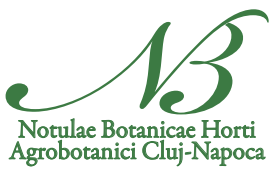

\title{
Transcriptome-wide identification and characterization of WD40 genes, as well as their tissue-specific expression profiles and responses to heat stress in Dimocarpus longan Lour.
}

\author{
Wei ZHENG ${ }^{1}$, Ziwei ZHANG ${ }^{1}$, Xuefei $\mathrm{YU}^{2}$, Tongtong XIE ${ }^{1}$, \\ Ning CHEN ${ }^{1}$, Wenlan $\mathrm{LI}^{1 *}$
}

\author{
${ }^{1}$ Harbin University of Commerce, School of Pharmacy, No. 138, Tongda Street, Daoli District, 150076, Harbin, \\ China; wei2013zheng@163.com; zzw19951216@163.com; xtt15663674920@163.com; chenning1981@126.com; \\ 1296893651@qq.com ("corresponding author) \\ ${ }^{2}$ Harbin University of Commerce, School of Library, No. 1, Xuehai Street, Songbei District, 150028, Harbin, China; \\ yuxuefei83@163.com
}

\begin{abstract}
The WD40 transcription factor (TF) family is widespread in plants and plays important roles in plant growth and development, transcriptional regulation, and tolerance to abiotic stresses. WD40 TFs have been identified and characterized in a diverse series of plant species. However, little information is available on $W D 40$ genes from $D$. longan. In this study, a total of $45 \mathrm{D} / W D 40$ genes were identified from $D$. longan RNASeq data, and further analysed by bioinformatics tools. Also, the expression patterns of DIWD40genes in roots and leaves, as well as responses to heat stress, were evaluated using quantitative real-time PCR (qRT-PCR). We found that the 45 DIWD 40 proteins, together with 80 WD 40 proteins from Arabidopsis and Zea mays, could be categorized into six groups. Of these, the DIWD40-4 protein was highly homologous to Arabidopsis WDR5a, a protein participating in tolerance to abiotic stresses. Moreover, a total of 25 cis-acting elements, such as abiotic stress and flavonoid biosynthesis elements, were found in the promoters of DIWD 40 genes. The DIWD40-33 gene is targeted by miR3627, which has been proposed to be involved in flavonoid biosynthesis. Using qRT-PCR, ten of the $45 \mathrm{D} / W D 40$ genes were demonstrated to have diverse expression patterns between roots and leaves, and these ten $D / W D 40$ genes could also respond to varying durations of a $38^{\circ} \mathrm{C}$ heat stress in roots and leaves. The results reported here will provide a basis for the further functional verification of D/WD 40 genes in D. longan.
\end{abstract}

Keywords: bioinformatics analysis; Dimocarpus longan Lour; gene expression; WD40 gene; thermal response

\section{Introduction}

Dimocarpus longan Lour. (D. longan), a member of the Sapindaceae family, is a perennial evergreen plant that is widely planted in humid and warm subtropical circumstances (Wang et al., 2015). D. longan is one of the major commercial crops in South China, Thailand, Vietnam, and other Southeast Asian countries,

Received: 14 Dec 2020. Received in revised form: 06 Feb 2021. Accepted: 17 Feb 2021. Published online: 25 Feb 2021.

From Volume 49, Issue 1, 2021, Notulae Botanicae Horti Agrobotanici Cluj-Napoca journal will use article numbers in place of the traditional method of continuous pagination through the volume. The journal will continue to appear quarterly, as before, with four annual numbers. 
where the growth environments of $D$. longan are very friendly (Hu et al., 2018b). The pulps, leaves, flowers, and roots of $D$. longan contain a variety of bioactive ingredients, such as flavonoids, tannins, and polysaccharides, thereby serving as traditional Chinese medicine to treat wounds, acariasis, and influenza (Ho et al., 2007; Xue et al., 2015). However, compared with the wide consumption of D. longan juicy fruit, the applications of $D$. longan roots and leaves as Chinese medicines have been constrained due to the little accumulation of active secondary metabolites. Moreover, the adverse environmental condition is another important factor negatively affecting the growth and quality of $D$. longan. Our previous studies suggested that the $4 \mathrm{bZIP}$ genes that were differently expressed between $D$. longan roots and leaves might be involved in the secondary metabolite accumulations (Zheng et al., 2020). In D. longan, the up-regulated expressions of WRKY1, WRKY8, and WRKY50 correspondingly contributed to the tolerance to drought, heat, and cold stresses, respectively (Jue et al., 2018). Therefore, it is urgent to investigate the key TF which not only participate in flavonoid biosynthesis but also enhance abiotic resistances.

WD40, a member of the broadly spread TF family in eukaryote species, is composed of WD40 repeats, which are characterized by a sequence of 40-60 amino acids (van Nocker and Ludwig 2003; Hu et al., 2018a). Each WD40 repeat typically starts with a Glycine-Histidine (GH) pair at the N-terminus and ends with a tryptophan-aspartic acid (WD) pair at the C-terminus (van Nocker and Ludwig 2003; Higa and Zhang 2007). Each WD40 repeat is composed of four-stranded antiparallel $\beta$-sheets, and can interact with other WD40 repeats to fold into a $\beta$-propeller, an important structure that enables WD 40 to perform many functions, such as mediating the protein-protein interactions (Nash et al., 2001; Fonseca and Rubio 2019; Ma et al., 2019). In addition, WD40 proteins are also involved in a variety of biological processes and tolerance to abiotic stresses (Li et al., 2014; Hu et al., 2018a). WD40 proteins can regulate flavonoid accumulation in various tissues by mediating the expression of flavonoid biosynthesis genes, including CHS, CHI, F3H, and DFR (Wu et al., 2015). For example, MdTTG1, a member of the WD40 family from apple, can interact with both bHLH and MYB to initiate the expression of $D F R$, a gene whose high expression promotes the biosynthesis of anthocyanin (An et al., 2012). The PhAN11 protein, the first identified WD40 family protein from Petunia hybrida Vilm, was demonstrated to increase the anthocyanin accumulation via activating the expression of the DFR gene (de Vetten et al., 1997). Arabidopsis TTG1 (homologs to PhAN11) could form four distinct protein complexes (TT2-TT8-TTG1, MYB5-TT8-TTG1, TT2-GL3-TTG1, and TT2-EGL3-TTG1) with MYB or bHLH proteins; these four complexes could up-regulate the expression of the DFR gene to increase anthocyanin accumulation (Xu et al., 2014).

In addition to their involvement in the biosynthesis of secondary metabolites, WD40 proteins have also been shown to participate in the tolerance to abiotic stresses, such as salt stress, drought stress, and heat stress. For example, the TTG1 gene from the Recretohalophyte limonium bicolor could help transgenic Arabidopsis to resist salt tolerance through both reducing epidermal ion accumulation and increasing osmotic pressure (Yuan et al., 2019). The TaWD40 transcription factor identified from wheat could respond to abiotic stresses. Heterologous over-expression of the TaWD 40 significantly enhanced the tolerance to salt stress and osmotic stress in Arabidopsis (Kong et al., 2015). The tolerance to drought stress was strengthened in Medicago sativa L. by enhancing the expression of WD40-1, the mechanism of which was due to the increasing content of anthocyanin (Feyissa et al., 2019). The TAWD protein, a member of the WD40 TF family from Arabidopsis, was involved in improving Arabidopsis resistance to high-temperature stress through activating the expression of heat-shock response (HSR) genes (Xia 2019).

Although the WD4OTF gene family has been intensively investigated in a variety of species, including potato, rice, and Arabidopsis (van Nocker and Ludwig 2003; Ouyang et al., 2012; Tao et al., 2019), little is known about WD40 TF genes for $D$. longan. In this study, we identified $45 \mathrm{D} / W D 40$ genes from $D$. longan RNA-Seq data and used bioinformatics tools to analyse their physiochemical properties, conserved motifs, evolutionary relationships, $\mathrm{GO}$ annotations, gene structures, promoter function prediction, protein-protein interactions, and miRNA targets. Additionally, qRT-PCR was used to detect their expression patterns in roots and leaves, as well as in response to heat stress, in order to identify key WD4OTF genes that both function in 
flavonoid accumulation and in tolerance to heat stress. The results of this study will provide a genetic resource for not only improving $D$. longan tolerance to abiotic stresses but also increasing flavonoid accumulation in $D$. longan leaves and roots through genetic engineering.

\section{Materials and Methods}

\section{Materials and growth conditions}

D. longan plants were planted in a greenhouse maintained at $25^{\circ} \mathrm{C}$ and relative humidity of $50 \%$. After 2 months of growth, leaves (picked from the upper peripheral branches) and roots gathered from ten plants. For the heat stress, the 2-month-old $D$. longan plants were exposed to a $38^{\circ} \mathrm{C}$ heat stress for $1,4,8$, or $24 \mathrm{~h}$. Then, the roots and leaves from $D$. longan were collected after heat stress at the given time points. All samples were immediately immersed in liquid nitrogen and then stored in a $-80{ }^{\circ} \mathrm{C}$ freezer for quantitative real-time PCR (qRT-PCR) analysis.

\section{Identification and bioinformatics analysis of D/WD40 proteins}

Based on RNA-Seq data of D. longan (NCBI accession number: SRP155595), a total of 45 putative DIWD 40 genes were identified. Using the NCBI CD-Search and the SMART tools, the WD40 domain and the quantities of WD40 repeat for 45 DIWD40 proteins were identified. The molecular weights, protein sequence lengths, aliphatic indices, instability indices, grand average of hydropathicity scores, isoelectric points, subcellular protein localization, motif predictions, miRNA targets, and functional regulatory networks of the D. longan DIWD40 proteins were comprehensively investigated using bioinformatics software (Table 1). The $D$. longan miRNAs used for the analysis of miRNA targets were downloaded from the results of Lin et al. (2013). Genes from the $D$. longan genome that were highly homologous to the $45 D / W D 40$ genes identified from RNA-Seq data were used as representatives to study the D/WD40gene structures and cis-acting elements. The visualization analysis of gene structures and conserved motifs were achieved using TBtools (Chen et al., 2020). Forty-five DIWD40 proteins, together with 80 WD 40 proteins from Arabidopsis thaliana and Zea mays, were used to construct a phylogenetic tree in MEGA 7.0 using the neighbour-joining method with 1000 bootstrap iterations. The functional classification of DIWD40 proteins into biological process, molecular function, and cellular component were generated by Blast2GO v5.0.

Table 1. On-line software for bioinformatics analysis

\begin{tabular}{|c|c|c|}
\hline Name & Web address & Function \\
\hline ORFfinder & https://www.ncbi.nlm.nih.gov/orffinder & Open reading frame prediction \\
\hline NCBI CD search & https://www.ncbi.nlm.nih.gov/Structure/bwrpsb/bwrpsb.cgi/ & Conservative domain prediction \\
\hline SMART & http://smart.embl-heidelberg.de/ & Conservative domain prediction \\
\hline ExPASY & https://web.expasy.org/protparam/ & $\begin{array}{c}\text { Physical and chemical properties } \\
\text { prediction }\end{array}$ \\
\hline SOPMA & https://npsa-prabi.ibcp.fr/cgi- \\
\hline WoLF PSORT & bin/npsa_automat.pl?page=npsa_sopma.html & Secondary structure prediction \\
\hline MEME & https://wolfpsort.hgc.jp/ & Subcellular localization prediction \\
\hline PlantCARE & http://meme-suite.org/tools/meme & Conserved motifs prediction \\
\hline psRATarget & http://bioinformatics.psb.ugent.be/webtools/plantcare/html/ & Cis response element prediction \\
\hline STRING & http://plantgrn.noble.org/psRNATarget/ & Plant small RNA target analysis server \\
\hline
\end{tabular}

$R N A$ isolation and quantitative real-time PCR analysis

RNA was extracted from the root and leaf tissues of $D$. longan using the cetyltrimethylammonium bromide (CTAB) method (Jaakola et al., 2001). TransScript ${ }^{\circ}$ One-Step gDNA Removal and cDNA Synthesis SuperMix kits (TransGen Biotech, Beijing, China) were used to obtain the first-strand cDNAs following the manufacturer' s instructions. Quantitative real-time PCR (qRT-PCR) reactions were performed to evaluate 
the expression levels of $D / W D 40$ genes using the TransStart ${ }^{\circ}$ Top Green qPCR SuperMix (TransGen Biotech, Beijing, China) according to the manufacturer' s instructions. The reaction system includes $10 \mu \mathrm{L}$ of $2 \times$ TransStart ${ }^{\circ}$ Top Green qPCR SuperMix, $1 \mu \mathrm{L}$ of cDNA template, $7 \mu \mathrm{L}$ of ddH2O, $1 \mu \mathrm{L}$ of forwarding primer, and $1 \mu \mathrm{L}$ of reverse primer (Table 2). The D. longan tubulin gene was chosen as a reference gene. The qRTPCR reaction parameters were set as follows: $95^{\circ} \mathrm{C}$ for $1 \mathrm{~min}$, followed by $95^{\circ} \mathrm{C}$ for $5 \mathrm{~s}, 60^{\circ} \mathrm{C}$ for $30 \mathrm{~s}$, and 72 ${ }^{\circ} \mathrm{C}$ for $30 \mathrm{~s}$. All assays were performed in triplicate. The $2^{-\Delta \Delta \mathrm{CT}}$ method was used to calculate the relative gene expression (Schmittgen and Livak 2008).

Table 2. Primer sequences for qRT-PCR

\begin{tabular}{|c|l|}
\hline Gene & \multicolumn{1}{c|}{ Primer sequence } \\
\hline$D / W D 40-4$ & $\begin{array}{l}\text { F: CAATGGTGCGACAGATGA } \\
\text { R: CCTCGGCAATGATAAGACT }\end{array}$ \\
\hline$D / W D 40-13$ & $\begin{array}{l}\text { F: GTAGTGGCTCTGCTGATAA } \\
\text { R: CAGTTATGACTCCAACCTTAC }\end{array}$ \\
\hline$D / W D 40-20$ & $\begin{array}{l}\text { F: CAATCCAAGCACATTCAGAG } \\
\text { R: CGGTAAGGTTACGACTAGC }\end{array}$ \\
\hline$D / W D 40-21$ & $\begin{array}{l}\text { F: CGGCTGGTAGATTGGAAG } \\
\text { R: TGCTGATGGACTGAAGGA }\end{array}$ \\
\hline$D / W D 40-22$ & $\begin{array}{l}\text { F: AGTTGTTGACGACGGAAG } \\
\text { R: CAAGCAATGGAGGAAGAGA }\end{array}$ \\
\hline$D / W D 40-25$ & $\begin{array}{l}\text { F: TGTTGAGGAGGTGGTGATA } \\
\text { R: GTAAGCAGAAGCCGACAA }\end{array}$ \\
\hline$D / W D 40-31$ & $\begin{array}{l}\text { F: GCCATCAATACAAGCACAA } \\
\text { R: AACGAGGTAATCAGACGAAT }\end{array}$ \\
\hline F: TGCTTCAATGGAGAACGAT \\
R: CAAGGATACTGGTGGAGATT
\end{tabular}

Results

\section{Identification and structural analysis of DIWD40 TFs from D. longan}

Based on $\mathrm{Nr}$ annotation, we obtained 45 putative $D / W D 40$ genes from RNA-Seq data of $D$. longan leaves and roots (accession number: SRP155595). Then CD search and SMART tools were used to further confirm their identities. For convenience, these genes were numbered from DIWD40-1 to D/WD40-45 according to the order in which they were identified from RNA-Seq data. In total, 45 DIWD40 proteins could be divided into two groups (Figure 1). The first group, including 34 DIWD40 proteins, was characterized as having only the WD40 domain in each DIWD40. The second group (11 DlWD40 proteins) not only contained the WD40 domain but also possessed other identified domains, such as Cytadhesin-P30, Med15, Bromo-WDR9-I-like, Coatomer-WDAD, Ge1-WD40, DUF4678, NLE, CAF1C-H4-bd, Katanin-con80, ATG16, Ufd2P-core, and ANAPC4. 

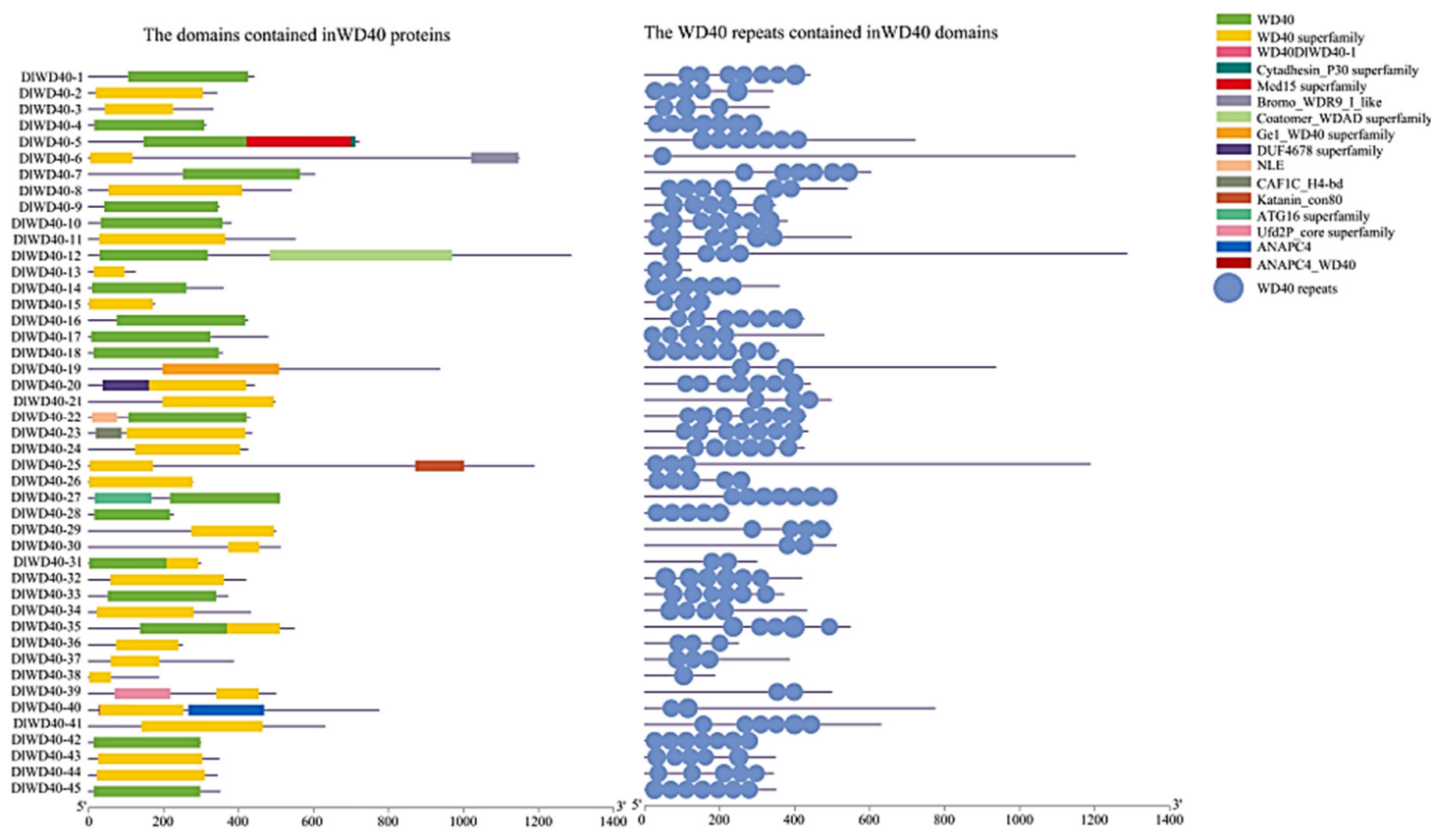

Figure 1. Identification and structural analysis of DIWD40 proteins

The protein structure is based on the presence of WD40 and other additional domains, as identified by SMART and CD search

\section{Physicochemical properties}

The physicochemical properties of DIWD40 proteins, including the length of open reading frames $(\mathrm{ORF})$, molecular weights (MW), isoelectric points (pI), aliphatic indices, instability indices (II), grand average of hydropathicity (GRAVY) scores, and subcellular localizations were evaluated using ExPASY. The results shown in Table 3 indicate that the length of DIWD 40 proteins varied from $124 \mathrm{bp}$ to $1286 \mathrm{bp}$, and the molecular weight ranges from 13,370.22 to $141,013.77$ Da. Among 45 DIWD40 proteins, 17 DIWD40s were acidic proteins, and 28 DIWD40s were basic proteins. The subcellular localization analysis showed that nearly half of the DIWD40 proteins were predicted to localize in the nuclear compartment, and the remaining were predicted to localize in the chloroplast, cytoplasm, plasma, mitochondrial, or peroxisome.

\section{Conserved motifs and gene structures}

The conserved motifs of 45 DIWD40 proteins were investigated by MEME. To analyse the gene structures, genes from the $D$. longan genome that were highly homologous to $45 \mathrm{D} / W D 40$ genes from $D$. longan RNA-Seq data were chosen as representatives (Table 4). TBtools was used to display the evolutionary relationship, conserved motifs, and gene structures of the 45 DlWD 40 proteins (Figure 2). A total of 15 motifs were identified from DIWD40 proteins. Of these, the motif2 was present in all the 45 DIWD 40 proteins. The motif3 and motif 4 were also widely spread, conserved by 41 and 43 DlWD 40 proteins, respectively. The gene structure analysis showed that the quantities of introns contained by $D / W D 40$ genes varied significantly. Particularly, there were no introns found in DIWD40-1, DIWD40-10, DIWD40-13, DIWD40-16, DIWD4020,DIWD40-23, DIWD40-36, and DIWD40-41. In addition, in group A or group B, formed based on the results of the phylogenetic tree, had similar motif compositions and quantities of introns/exons. 
Table 3. Physicochemical properties and subcellular localization of DIWD40 proteins

\begin{tabular}{|c|c|c|c|c|c|c|c|c|}
\hline Name & ID & ORF (aa) & PI & $\begin{array}{l}\text { Aliphatic } \\
\text { index }\end{array}$ & $\mathrm{MW}(\mathrm{Da})$ & $\begin{array}{l}\text { Instability } \\
\text { index (II) }\end{array}$ & GRAVY & $\begin{array}{l}\text { Subcellular } \\
\text { localization }\end{array}$ \\
\hline DIWD40-1 & c32248.graph_c0 & 441 & 8.82 & 73.61 & 48131.50 & 41.26 & -0.349 & nuclear \\
\hline DIWD40-2 & c38259.graph_c0 & 342 & 8.66 & 67.54 & 37961.53 & 38.53 & -5.040 & chloroplasmat \\
\hline DIWD40-3 & c33075.graph_c0 & 332 & 9.53 & 78.13 & 36225.96 & 33.35 & -0.336 & nuclear \\
\hline DIWD40-4 & c33149.graph_c0 & 313 & 6.78 & 75.27 & 34719.94 & 25.19 & -0.322 & chloroplasmat \\
\hline DIWD40-5 & c32029.graph_c0 & 721 & 8.71 & 49.24 & 79614.81 & 57.48 & -0.753 & nuclear \\
\hline DIWD40-6 & c29449.graph_c0 & 1148 & 5.80 & 67.78 & 130309.09 & 52.31 & -0.805 & peroxisome \\
\hline DIWD40-7 & c36465.graph_c0 & 603 & 5.13 & 77.15 & 67847.41 & 44.98 & -0.444 & nuclear \\
\hline DIWD40-8 & c11378.graph_c0 & 540 & 4.23 & 74.00 & 59943.59 & 38.51 & -0.562 & cytoplasm \\
\hline DIWD40-9 & c11668.graph_c0 & 348 & 4.95 & 82.93 & 38507.36 & 41.32 & -0.202 & nuclear \\
\hline DIWD40-10 & c29035.graph_c0 & 380 & 9.45 & 85.61 & 42233.32 & 38.19 & -0.299 & chloroplasmat \\
\hline DIWD40-11 & c36606.graph_c0 & 551 & 4.77 & 86.30 & 60714.61 & 42.51 & -0.337 & nuclear \\
\hline DIWD40-12 & c35681.graph_c0 & 1286 & 8.71 & 92.44 & 141013.77 & 40.28 & -0.107 & nuclear \\
\hline DIWD40-13 & c38763.graph_c0 & 124 & 6.80 & 78.55 & 13370.22 & 26.39 & -0.127 & cytoplasm \\
\hline DIWD40-14 & c33142.graph_c0 & 359 & 7.64 & 82.23 & 39137.13 & 28.17 & -0.251 & mitochondrial \\
\hline DIWD40-15 & c35955.graph_c1 & 176 & 5.36 & 75.80 & 20341.16 & 61.22 & -0.250 & chloroplasmat \\
\hline DIWD40-16 & c18112.graph_c0 & 424 & 8.10 & 87.10 & 47494.79 & 34.02 & -0.303 & chloroplasmat \\
\hline DIWD40-17 & c27535.graph_c0 & 478 & 8.55 & 76.30 & 53388.72 & 41.47 & -5.502 & nuclear \\
\hline DIWD40-18 & c31285.graph_c0 & 357 & 4.81 & 67.20 & 39846.31 & 38.88 & -0.394 & nuclear \\
\hline DIWD40-19 & c36726.graph_c0 & 913 & 5.30 & 76.55 & 99021.77 & 55.08 & -0.452 & chloroplasmat \\
\hline DIWD40-20 & c31155.graph_c0 & 442 & 8.80 & 74.77 & 48653.05 & 45.08 & -0.309 & chloroplasmat \\
\hline DIWD40-21 & c26705.graph_c0 & 497 & 5.03 & 73.88 & 55857.16 & 40.31 & -0.557 & nuclear \\
\hline DIWD40-22 & c32711.graph_c0 & 430 & 5.74 & 87.95 & 47483.61 & & -0.205 & nuclear \\
\hline DIWD40-23 & c27808.graph_c0 & 435 & 8.90 & 88.48 & 47548.09 & & -0.138 & chloroplasmat \\
\hline DIWD40-24 & c32525.graph_c0 & 425 & 4.77 & 77.53 & 48470.88 & & -0.611 & nuclear \\
\hline DIWD40-25 & c30425.graph_c0 & 1188 & 8.23 & 73.59 & 131992.02 & 40.57 & -0.445 & plasma \\
\hline DIWD40-26 & c30662.graph_c0 & 277 & 6.99 & 82.27 & 31226.35 & 37.79 & -0.236 & cytoplasm \\
\hline DIWD40-27 & c35209.graph_c0 & 510 & 5.97 & 90.49 & 5615.29 & 42.72 & -0.299 & cytoplasm \\
\hline DIWD40-28 & c33988.graph_c0 & 226 & 8.12 & 87.57 & 24978.50 & 28.29 & -0.019 & mitochondrial \\
\hline DIWD40-29 & c34516.graph_c0 & 449 & 5.37 & 81.32 & 55698.84 & 39.88 & -0.347 & nuclear \\
\hline DIWD40-30 & c31803.graph_c0 & 511 & 8.83 & 76.26 & 57266.56 & 43.53 & -0.462 & nuclear \\
\hline DIWD40-31 & c29207.graph_c0 & 299 & 5.78 & 81.14 & 33502.76 & 32.58 & -0.205 & chloroplasmat \\
\hline DIWD40-32 & c29433.graph_c0 & 419 & 4.92 & 60.79 & 46840.42 & 42.15 & -0.529 & nuclear \\
\hline DIWD40-33 & c29959.graph_c0 & 371 & 5.21 & 87.01 & 41474.71 & 29.79 & -0.266 & mitochondrial \\
\hline DIWD40-34 & c17995.graph_c0 & 432 & 5.81 & 92.92 & 46319.52 & 36.14 & -0.049 & cytoplasm \\
\hline DIWD40-35 & c26597.graph_c0 & 548 & 7.65 & 73.28 & 58643.42 & 40.26 & -0.341 & nuclear \\
\hline DIWD40-36 & c16392.graph_c0 & 250 & 9.17 & 82.56 & 27531.38 & 50.07 & -0.151 & cytoplasm \\
\hline DIWD40-37 & c27876.graph_c0 & 386 & 4.97 & 73.21 & 42283.02 & 46.34 & -0.291 & nuclear \\
\hline DIWD40-38 & c33292.graph_c0 & 187 & 5.74 & 84.01 & 20548.47 & 32.28 & -0.071 & cytoplasm \\
\hline DIWD40-39 & c32008.graph_c0 & 499 & 5.62 & 80.14 & 55982.30 & 38.46 & -0.248 & nuclear \\
\hline DIWD40-40 & c34466.graph_c0 & 774 & 5.10 & 94.43 & 87650.03 & 43.41 & -0.183 & nuclear \\
\hline DIWD40-41 & c31315.graph_c0 & 630 & 6.90 & 67.38 & 69852.77 & 40.92 & -0.588 & nuclear \\
\hline DIWD40-42 & c31433.graph_c0 & 299 & 6.41 & 79.77 & 33176.17 & 35.46 & -0.338 & cytoplasm \\
\hline DIWD40-43 & c35926.graph_c0 & 348 & 8.60 & 62.76 & 38581.51 & 40.26 & -0.454 & nuclear \\
\hline DIWD40-44 & c13993.graph_c0 & 343 & 5.61 & 76.73 & 37953.84 & 51.02 & -0.225 & cytoplasm \\
\hline DIWD40-45 & c31065.graph_c0 & 350 & 5.56 & 69.94 & 38158.59 & 39.80 & -0.380 & nuclear \\
\hline
\end{tabular}


Table 4. Selected genes from the $D$. longan genome that were highly homologous to $D / W D 40$ genes identified from the $D$. longan RNA-Seq data

\begin{tabular}{|c|c|c|c|c|c|c|c|}
\hline $\begin{array}{l}\text { Gene } \\
\text { Name }\end{array}$ & $\begin{array}{c}\text { Homologous } \\
\text { gene ID }\end{array}$ & E-value & Identities & $\begin{array}{l}\text { Gene } \\
\text { name }\end{array}$ & $\begin{array}{c}\text { Homologous } \\
\text { gene ID }\end{array}$ & E-value & Identities \\
\hline DIWD $40-1$ & Dlo_029802.1 & 0 & $99 \%$ & DIWD $40-24$ & Dlo_007184.1 & 0 & $94 \%$ \\
\hline DIWD $40-2$ & Dlo_012102.2 & 0 & $94 \%$ & DIWD $40-25$ & Dlo_011162.1 & 0 & $97 \%$ \\
\hline DIWD $40-3$ & Dlo_020391.1 & 0 & $100 \%$ & $D / W D 40-26$ & Dlo_009963.1 & 0 & $99 \%$ \\
\hline DIWD $40-4$ & Dlo_000498.1 & 0 & $99 \%$ & DIWD $40-27$ & Dlo_017783.1 & 0 & $97 \%$ \\
\hline DIWD $40-5$ & Dlo_024415.1 & 0 & $100 \%$ & DIWD $40-28$ & Dlo_023866.1 & $\mathrm{e}^{-160}$ & $100 \%$ \\
\hline DIWD $40-6$ & Dlo_024984.1 & 0 & $47 \%$ & DIWD $40-29$ & Dlo_030348.1 & 0 & $83 \%$ \\
\hline DIWD40-7 & Dlo_002488.1 & 0 & $93 \%$ & $D / W D 40-30$ & Dlo_029559.1 & 0 & $98 \%$ \\
\hline DIWD $40-8$ & Dlo_024199.4 & 0 & $98 \%$ & DIWD $40-31$ & Dlo_010650.1 & $\mathrm{e}^{-167}$ & $100 \%$ \\
\hline DIWD40-9 & Dlo_015366.1 & 0 & $99 \%$ & DIWD $40-32$ & Dlo_011186.1 & 0 & $99 \%$ \\
\hline DIWD $40-10$ & Dlo_023261.1 & 0 & $99 \%$ & DIWD40-33 & Dlo_028362.1 & 0 & $99 \%$ \\
\hline DIWD40-11 & Dlo_030845.1 & 0 & $90 \%$ & DIWD $40-34$ & Dlo_023879.2 & 0 & $85 \%$ \\
\hline D/WD $40-12$ & Dlo_000205.1 & 0 & $92 \%$ & DIWD $40-35$ & Dlo_011062.2 & 0 & $73 \%$ \\
\hline D/WD $40-13$ & Dlo_028595.1 & $5.00 \mathrm{E}^{-76}$ & $91 \%$ & DIWD40-36 & Dlo_028595.1 & $\mathrm{e}^{-153}$ & $88 \%$ \\
\hline D/WD $40-14$ & Dlo_014634.5 & $\mathrm{e}^{-162}$ & $78 \%$ & $D / W D 40-37$ & Dlo_014196.1 & 0 & $99 \%$ \\
\hline D/WD $40-15$ & Dlo_009332.1 & $\mathrm{e}^{-131}$ & $100 \%$ & DIWD $40-38$ & Dlo_024747.1 & $\mathrm{e}^{-116}$ & $91 \%$ \\
\hline DIWD $40-16$ & Dlo_012369.1 & 0 & $99 \%$ & DIWD40-39 & Dlo_030441.4 & 0 & $80 \%$ \\
\hline D/WD $40-17$ & Dlo_019591.1 & 0 & $100 \%$ & DIWD $40-40$ & Dlo_011184.1 & 0 & $99 \%$ \\
\hline$D / W D 40-18$ & Dlo_009693.1 & 0 & $100 \%$ & $D / W D 40-41$ & Dlo_018435.1 & $\mathrm{e}^{-145}$ & $81 \%$ \\
\hline D/WD40-19 & Dlo_020796.1 & 0 & $89 \%$ & $D / W D 40-42$ & Dlo_007490.2 & 0 & $92 \%$ \\
\hline DIWD $40-20$ & Dlo_004272.1 & 0 & $100 \%$ & $D / W D 40-43$ & Dlo_006201.1 & 0 & $96 \%$ \\
\hline$D / W D 40-21$ & Dlo_012604.1 & 0 & $94 \%$ & DIWD40-44 & Dlo_007375.1 & 0 & $99 \%$ \\
\hline DIWD $40-22$ & Dlo_004320.1 & 0 & $95 \%$ & DIWD $40-45$ & dlo_038010.1 & 0 & $97 \%$ \\
\hline DIWD $40-23$ & Dlo_032379.1 & 0 & $91 \%$ & & & & \\
\hline
\end{tabular}

\section{Phylogenetic analysis}

An unrooted phylogenetic tree was constructed using MEGA 7.0 to analyze the evolutionary relationships among 125 WD40 proteins (45 DlWD40 proteins from D. longan, 40 WD 40 proteins from Arabidopsis thaliana, and 40 WD40 proteins from Zea mays) (Figure 3). Apart from six WD40 proteins not classified into any group, a total of 119 WD40 proteins were categorized into six groups following the strategy that was adopted in rice and Arabidopsis thaliana (Ouyang et al., 2012). Group 1 was the largest, containing 49 WD40 proteins, whereas group 6 was the smallest, with only 5 WD40 proteins in this group. Importantly, the DIWD40-4 proteins were highly homologous to the Arabidopsis thaliana WDR5a protein, a protein involved in tolerance to abiotic stresses (Liu et al., 2018). Although the TTG1 protein from Arabidopsis thaliana was another important WD40 protein functioning in anthocyanin accumulation, we, unfortunately, did not find any DIWD40 proteins that were highly homologous to the TTG1 protein. 


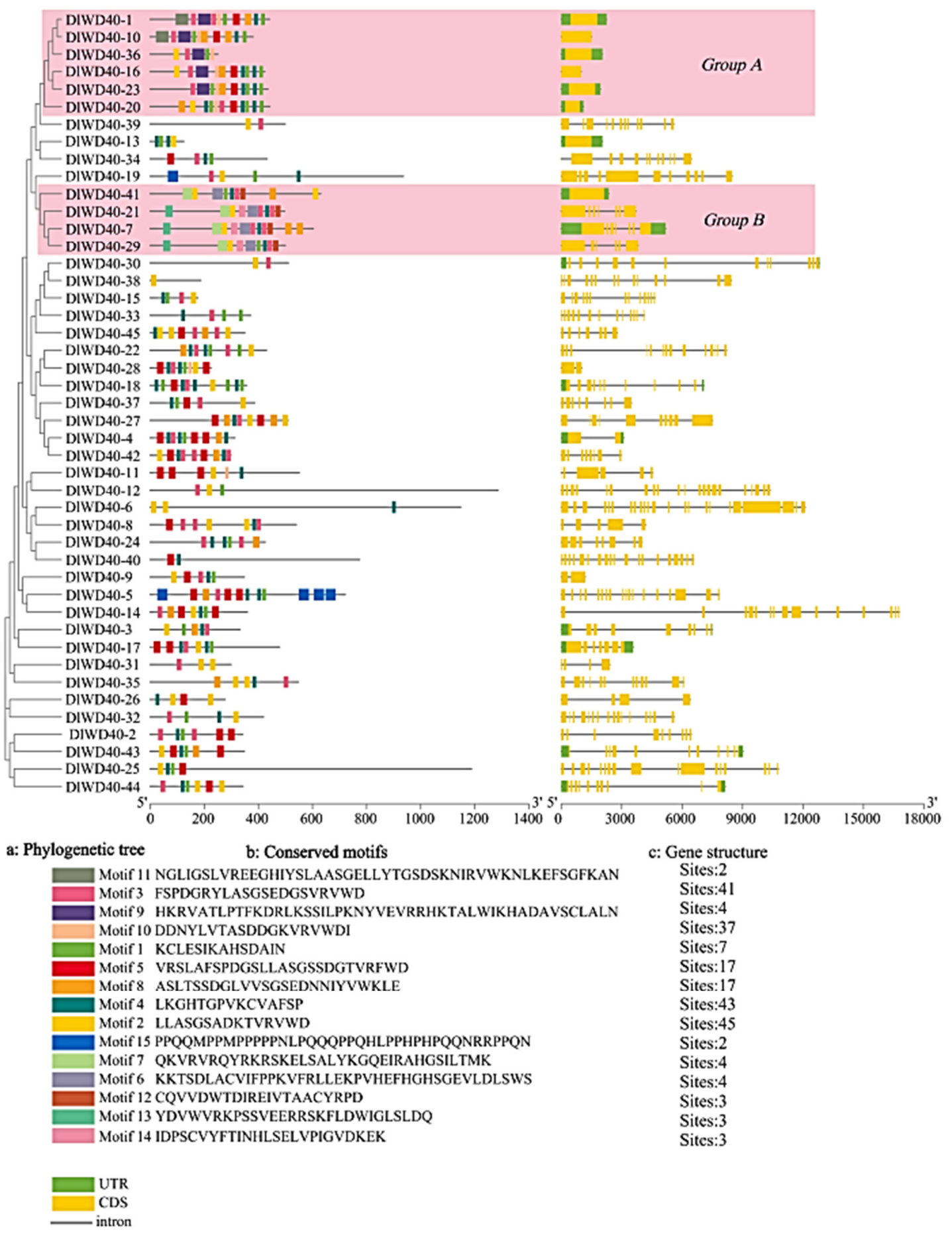

Figure 2. Phylogenetic relationships, cconserved motifs, and gene structure of the DIWD 40 genes (a) The phylogenetic tree was constructed by Maximum Likelihood (ML) with bootstrap 1000. (b) The conserved motifs was elucidated using MEME. Each motif is represented by a coloured box. (c) Gene structure. The UTR, CDS and introns are represented by green boxes, yellow boxes, and grey lines, respectively. In the legend, capital letters were used to indicate amino acid sequences of 15 motifs and the numbers after sites indicate the number of motifs appearing in DIWD40 proteins 


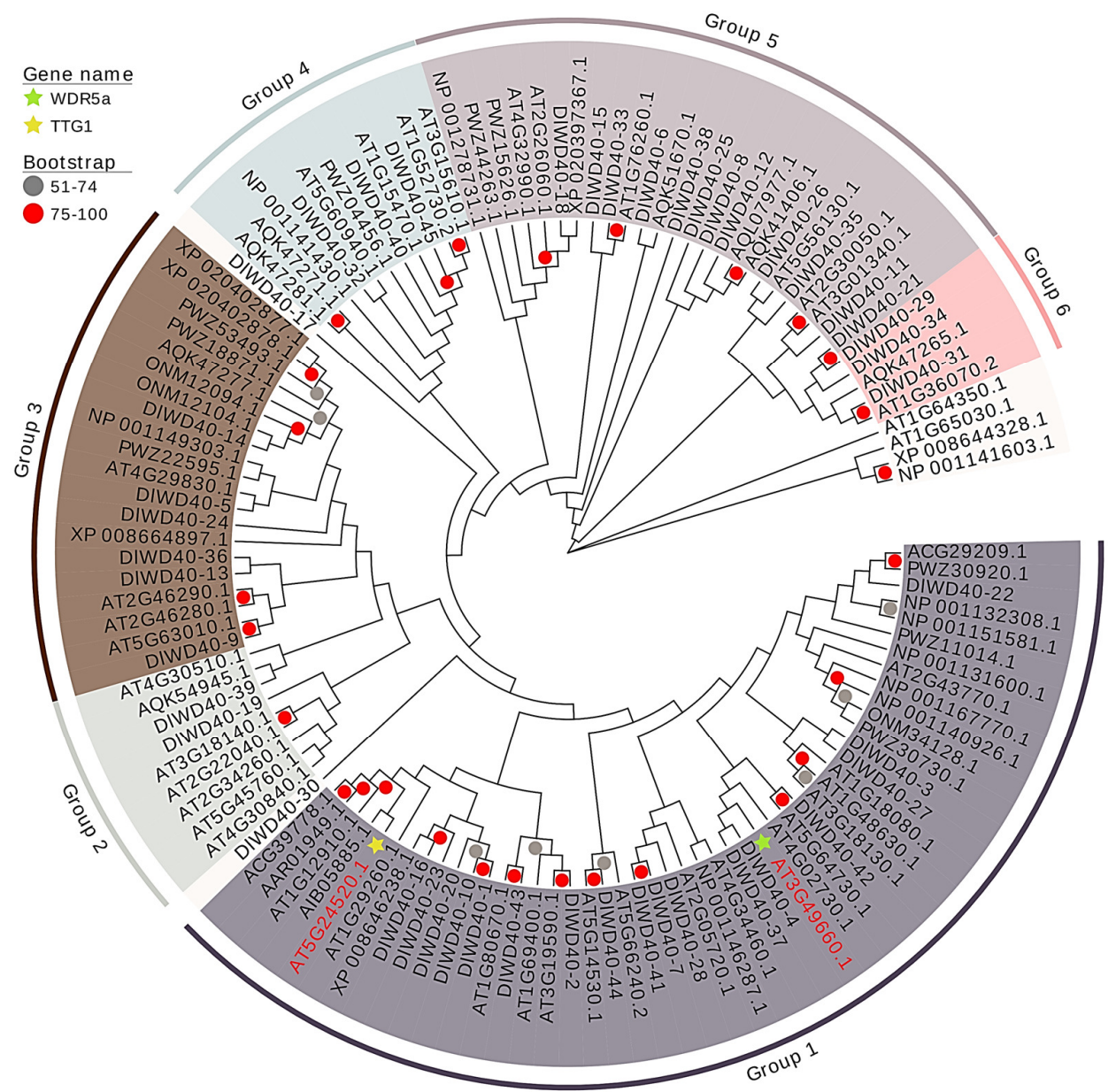

Figure 3. Phylogenetic tree of WD40 proteins from D. longan, Arabidopsis thaliana, and Zea mays

\section{Gene ontology (GO) annotation}

The functions of DIWD 40 proteins were annotated using Blast2GO v5.2.5. All 45 DIWD40 proteins were classified into three major categories: biological process, cellular component, and molecular function (Figure 4). In the biological process, 45 DlWD40 proteins could be further divided into 13 functional subcategories, of which the cellular process (21 DIWD40 proteins), metabolic process (19 DIWD40 proteins), and cellular component organization or biogenesis (13 DlWD40 proteins) were the first three largest functional subcategories. In molecular function, all 45 DIWD 40 proteins were functionally related to binding; thirteen DIWD40 proteins were predicted to be associated with catalytic activity. Three terms were assigned to cellular components, which were intracellular (20 DIWD40 proteins), cellular anatomical entity (21 DIWD40 proteins) and protein-containing complex (16 DlWD40 proteins). 


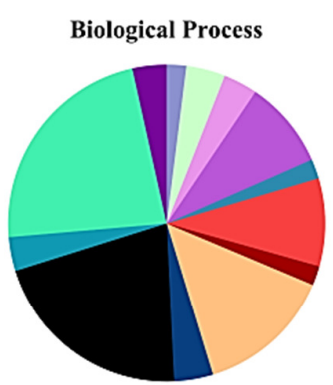

$\mathbf{a}$

\section{Cellular Component}

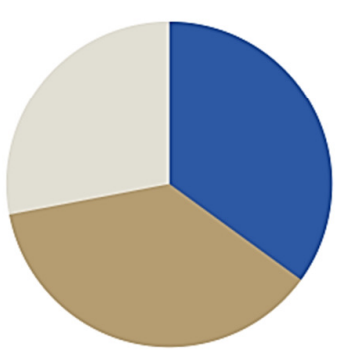

c

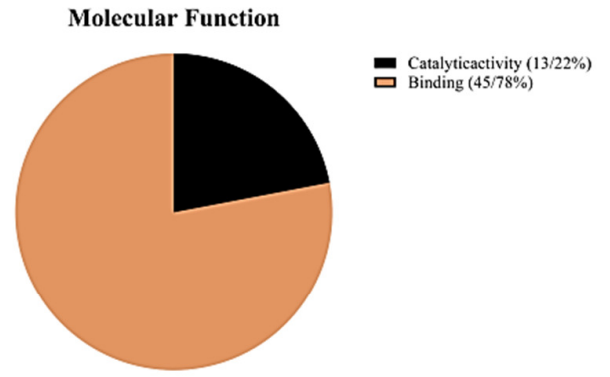

b

Figure 4. Gene Ontology (GO) annotation results for 45 DIWD40 proteins from D. longan. (a) biological processes, (b) molecular functions, and (c) cellular components

\section{Analysis of promoter and miRNA targets}

To further predict the putative functions of DIWD 40 genes, PlantCARE was used to analyse the cisacting elements in the promoter region of the 45 D/WD 40 genes. The results are shown in Figure 5:25 main types of cis-regulatory elements were detected, including hormone response elements (abscisic acid, gibberellin, methyl jasmonate, and salicylic acid), abiotic stress response elements (anaerobic, low-temperature, light, drought, and wound), MYB response elements, and other response elements related to plant growth and development. The compositions and quantities of cis-elements in the promoter of each DIWD 40 gene are systematically displayed in Figure 5. The light response elements (G-box, I-box, AE-box, and Box-4) that were conserved by all the 45 DIWD 40 proteins were found to present in a large number.

miRNAs are a class of single-stranded non-coding RNAs (18-25 nt in length) that negatively regulate gene expression by cleaving targeted mRNAs and repressing translation. In this study, we used psRNATarget to explore the $D$. longan miRNAs that could target on $D / W D 40$ genes. The results shown in Figure 6 indicate that the regulatory networks of miRNA-gene were complicated. It can be seen that a DIWD 40 gene could be targeted by more than one miRNA, suggesting that the expressions of D/WD 40 genes might be repressed by various miRNAs. It is noteworthy that the expressions of D/WD40-5, DIWD40-6, and D/WD40-25 genes were predicted to be negatively regulated by five diverse miRNAs via either cleaving targeted mRNAs or repressing translation. It is noteworthy that miRNA1150, miRNA1078, miRNA2595, miRNA2673a, miRNA2930, and miRNA5170 could regulate different D/WD40 genes in the same way, while miRNA1150 operated by a different mechanism. 


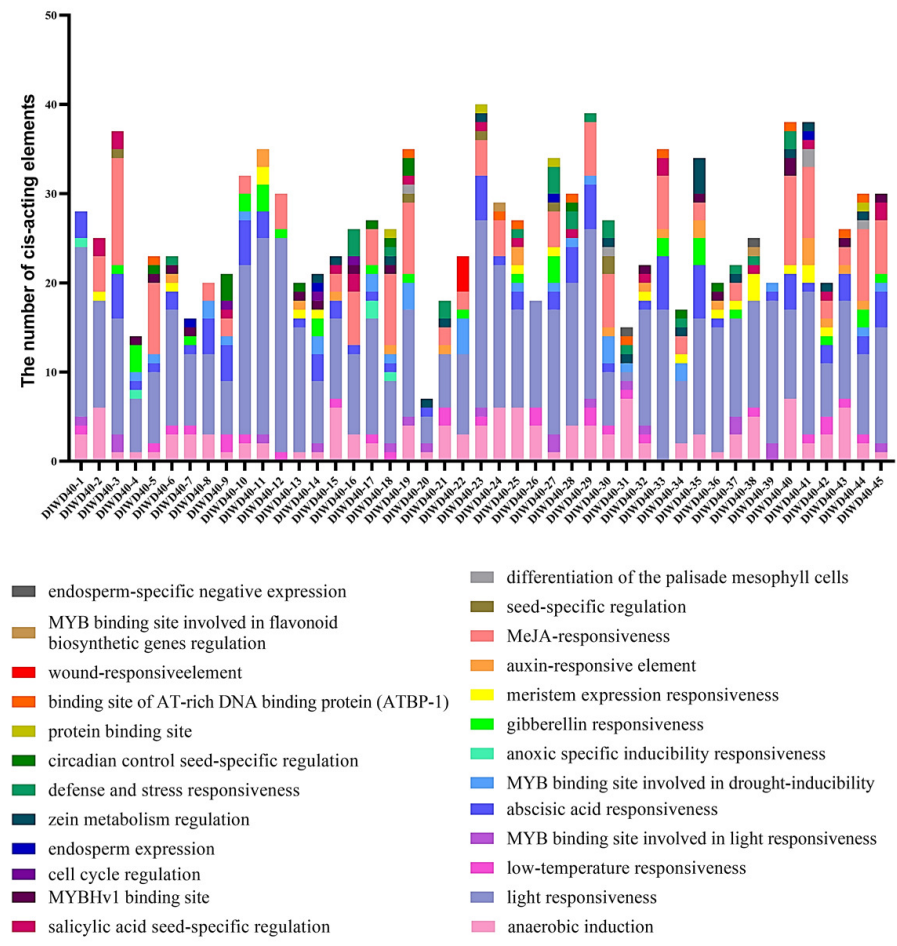

Figure 5. Compositions of the cis-acting element of $45 \mathrm{DIWD} 40$ s from D. longan

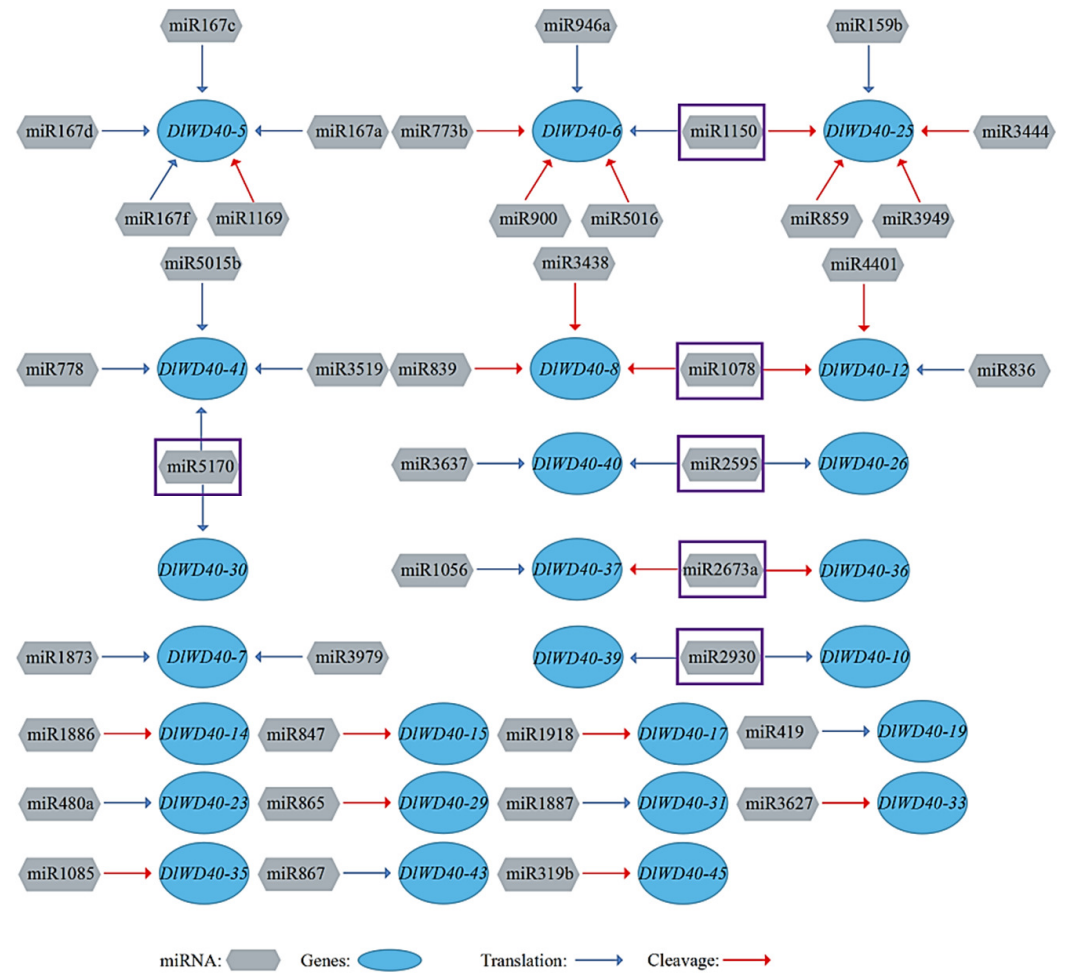

Figure 6. The network of putative miRNA targeting the DIWD 40 genes

The miRNA regulating more than one gene were marked by purple boxes. The top $E$-value was no more than 3.5 (lower $E$-values correspond to higher credibility of miRNA regulatory genes) 


\section{Protein-protein interactions}

The STRING tool was used in this study to investigate the protein-protein interactions among DIWD40 proteins. STRING was unable to directly study the DIWD40 protein interactions because the $D$. longan genomic data were not available in the STRING database. To solve this problem, the Arabidopsis WD40 proteins that were highly homologous to DIWD40 proteins were chosen as representative sequences for the analysis of protein interactions. To a certain extent, the Arabidopsis WD40 protein interactions could be used to reveal the interactions of the DIWD 40 proteins in $D$. longan, since orthologous proteins usually have similar biological functions (Li et al., 2005).

As shown in Figure 7, 17 DIWD40 proteins (DIWD40-2, DIWD40-4, DIWD40-5, DIWD40-6, DIWD40-8, DIWD40-15, DIWD40-18, DIWD40-20, DIWD40-22, DIWD40-24, DIWD40-28, DIWD4035, DIWD40-36, DIWD40-40, DIWD40-43, and DIWD40-44) linked with other proteins by purple lines, indicating that the protein-protein interactions were validated experimentally. Among these, DIWD-44 (homologous to AT5G14530), DIWD40-28 (homologous to WDR5b), DIWD40-11 (homologous to AT3G21060), DIWD40-5 (homologous to FY), DIWD40-40 (homologous to APC4), and DlWD40-4 (homologous to WDR5a) could each interact with more than three proteins. Unfortunately, the DIWD39 protein was not found to be homologous to any Arabidopsis WD40 proteins. Also, 13 DIWD40 proteins (DlWD40-1, DlWD40-7, DIWD40-9, DlWD40-10, DIWD40-12, DlWD40-17, DIWD40-21, DlWD4025, DIWD40-26, DlWD40-29, DIWD40-33, DIWD40-38, and DlWD40-41) were not found to have protein-protein interactions.

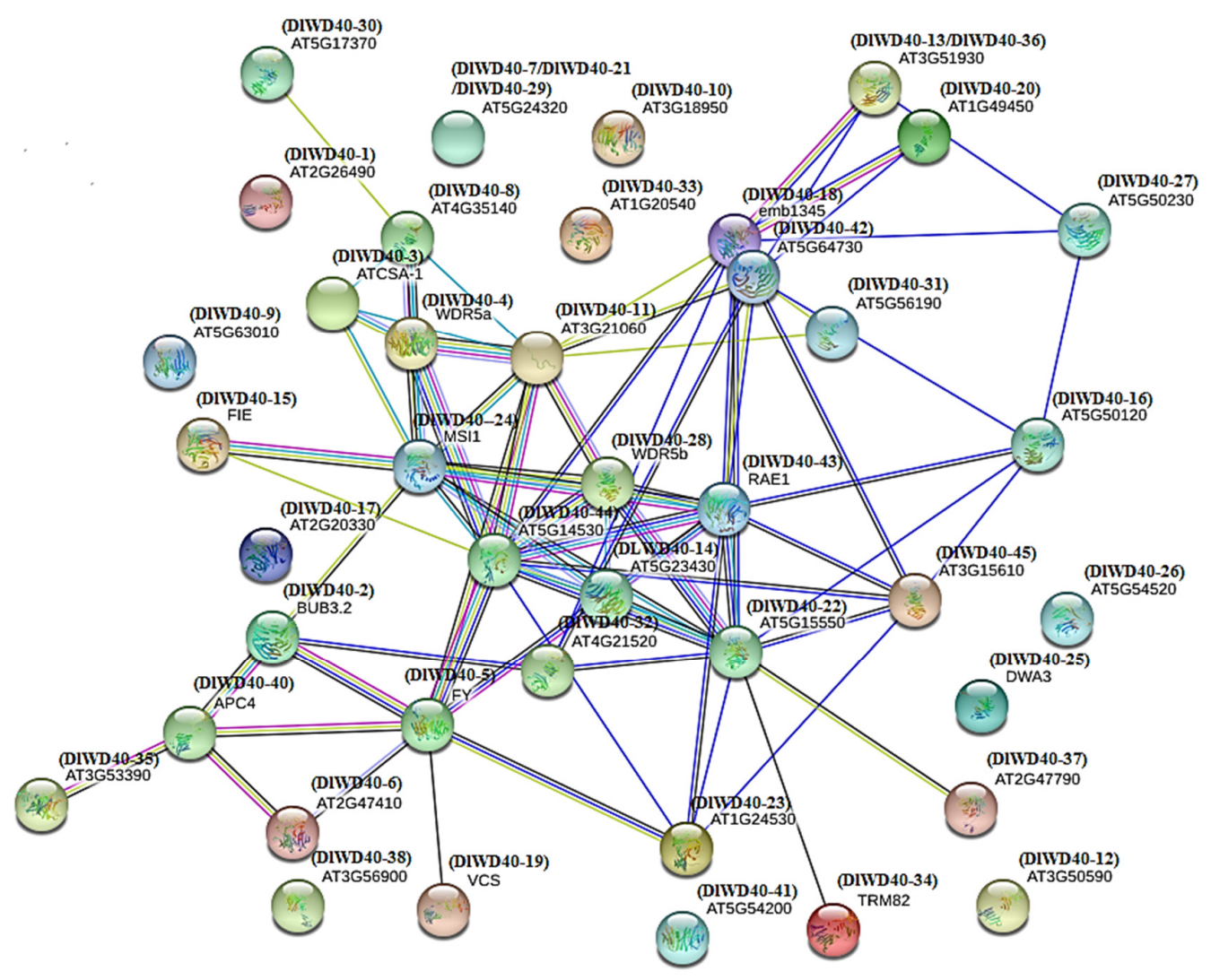

Figure 7. Protein interaction network of DIWD40 proteins from D. longan

Purple lines indicate experimentally validated protein interactions; green lines indicate predicted protein interactions based on gene neighbourhood; blue lines indicate predicted protein interactions based on gene co-occurrence; and black lines indicate protein co-expression 


\section{Expression levels of DIWD 40 genes in root and leaf tissues from D. longan}

The expression levels of $D / W D 40$ genes in $D$. longan roots and leaves were retrieved from $D$. longan RNA-Seq data and shown as a heat map in Figure 8. Ten $D / W D 40$ genes were identified to exhibit varied expression levels in roots and leaves (DIWD40-4, DIWD40-20, DIWD40-21, DIWD40-25, DIWD40-31, DIWD40-13, DIWD40-22, DIWD40-32, DIWD40-36, and D/WD40-38). Next, the expression patterns of these ten $D / W D 40$ genes were further verified by qRT-PCR, the results of which were generally consistent with that acquired from RNA-Seq data (Figure 9). DIWD40-13, DIWD40-22, DIWD40-32, DIWD40-36, and DIWD40-38 were highly expressed in roots, whereas DIWD40-4, DIWD40-20, DIWD40-21, DIWD4025 , and $D / W D 40-31$ were highly expressed in leaves. It is noteworthy that the expression levels of the DIWD40-20 between roots and leaves were significantly different. The expression level of the D/WD40-20 in leaves was nearly 15 -fold higher than that in roots.

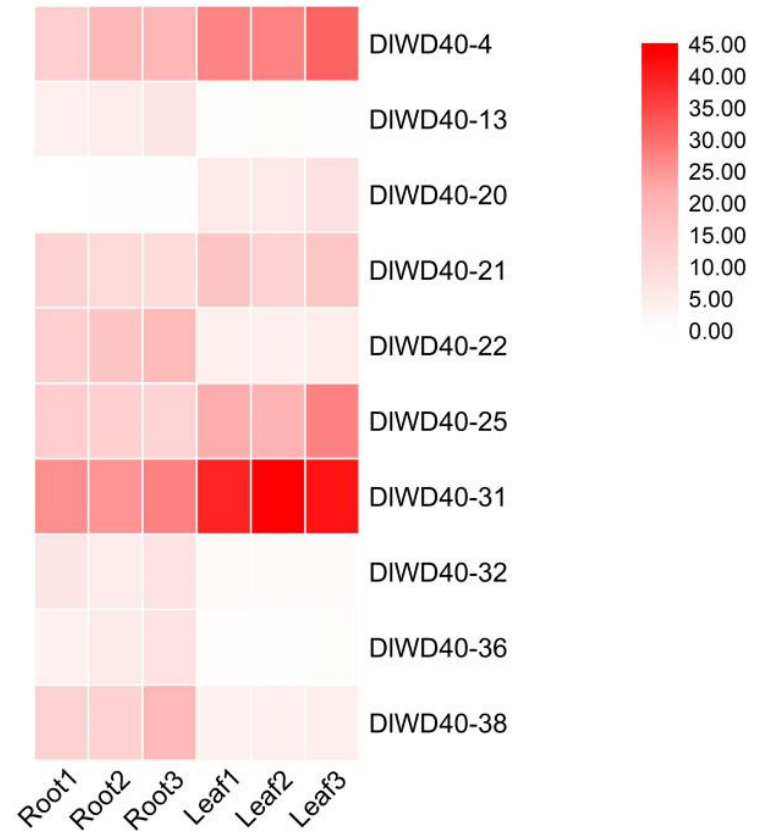

Figure 8. Heatmap showing the expression profiles of the $D / W D 40$ genes that were differentially expressed between $D$. longan roots and leaves

\section{Expression levels of D/WD 40 genes in root and leaf tissues under heat treatments}

qRT-PCR was used to further study whether or not these ten tissue-specific expression D/WD40 genes could respond under $38^{\circ} \mathrm{C}$ heat treatments for $1,4,8$, or $24 \mathrm{~h}$. We found that the expression levels of all ten $D / W D 40$ genes could be influenced by high-temperature stresses (Figure 10). In general, the expression levels of ten $D / W D 40$ genes first increased and then decreased during the heat stresses from 0 to $24 \mathrm{~h}$, although some $D I W D 40$ genes rebounded at $24 \mathrm{~h}$. In roots, the expression levels of the DIWD40-4, DIWD40-20, DIWD4025, and DIWD40-31 genes under heat stresses were more than 3-fold higher than the expression levels of $0 \mathrm{~h}$. Of these, the expression level of the DIWD40-25 gene in leaves was also very high after $24 \mathrm{~h}$ heat stress, approximately 3.5 -fold that at the $0 \mathrm{~h}$ time point. 

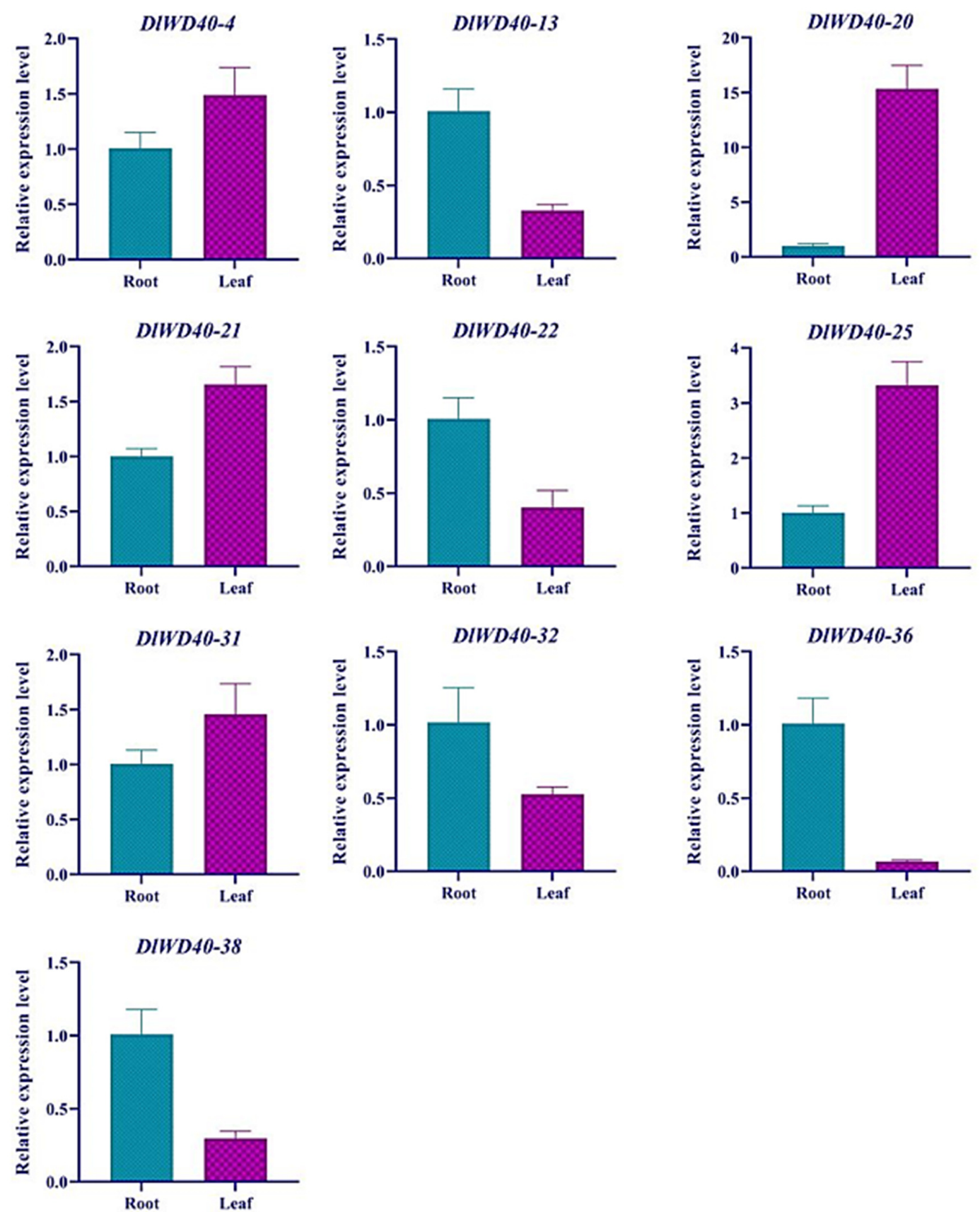

Figure 9. Expression patterns of $D / W D 40$ genes in roots and leaves of $D$. longan; error bars represent standard error of three independent replicates 

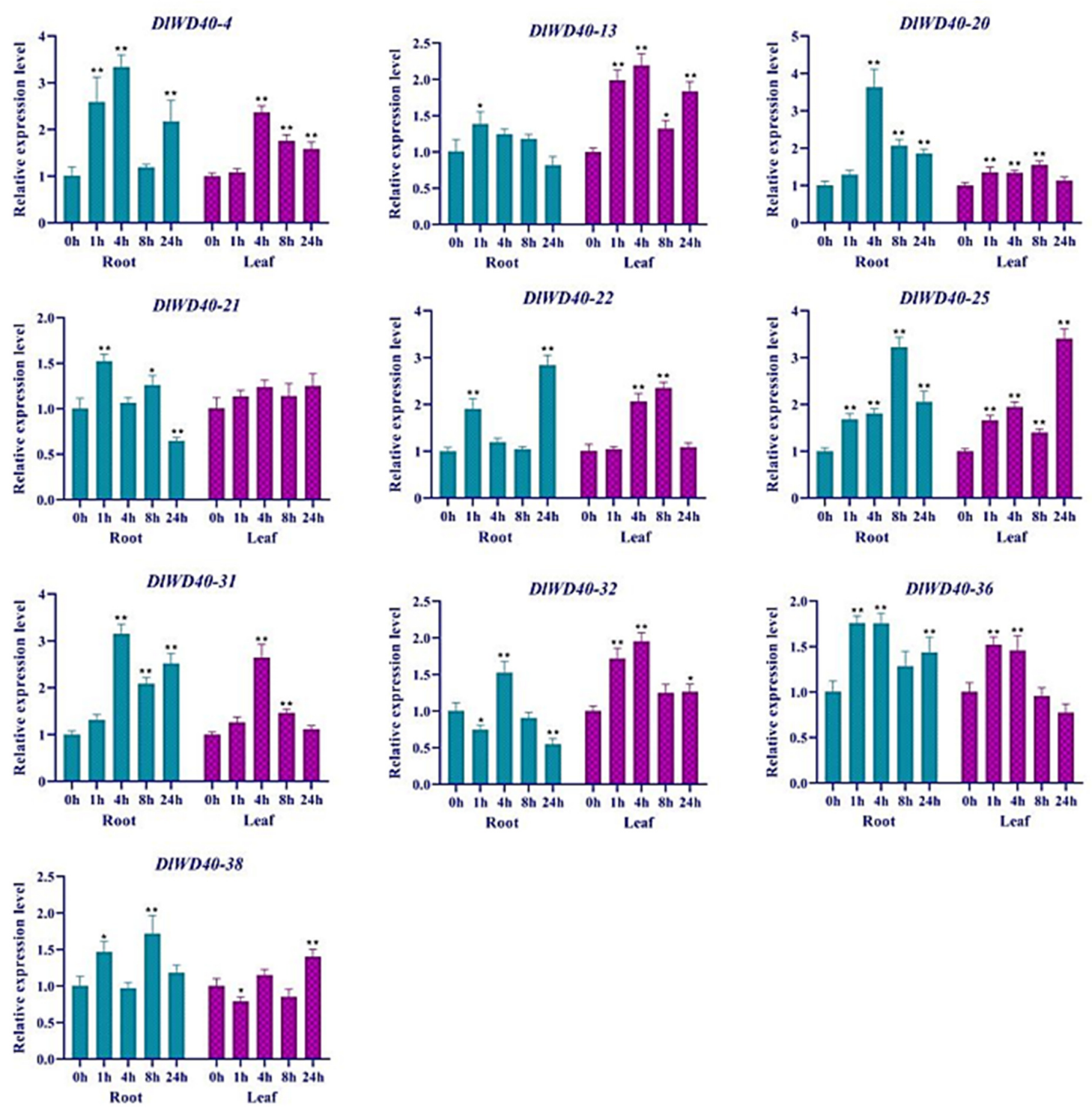

Figure 10. Stress responses of $D / W D 40$ genes under a $38^{\circ} \mathrm{C}$ heat treatment for $1,4,8$, or $24 \mathrm{~h}$ in $D$. longan root and leaf tissues

Asterisks indicate that the value is significantly different from that of the $0 \mathrm{~h}$ treatment $\left({ }^{*} \mathrm{p}<0.05,{ }^{* *} \mathrm{p}<0.01\right)$

\section{Discussion}

D. longan, a sort of very delicious fruit, can serve as traditional Chinese herbal medicine because of the pharmacological activities of its chemical constituents (Xue et al., 2015). D. Longan has been extensively used to promote blood metabolism and relieve insomnia (Huang et al., 2019). By contrast, the D. longan roots and leaves are also used as traditional Chinese herbal medicine, but are not widely applied due to the little accumulation of flavonoids and other important secondary metabolites. Furthermore, the circumstance (e.g., high temperature) where the $D$. longan usually grows was another important factor adversely affecting their qualities and yields (Jue et al., 2018). Studies have shown that the biosynthesis of flavonoids, a complex biological process, is regulated by the WD40 TF family in plants (Liu et al., 2013). WD40 TFs can interact 
with bHLH and MYB TFs to form complexes that could regulate the transcriptional levels of related genes, thereby affecting the anthocyanin synthesis in plants (Qin et al., 2020). In addition, the WD40 TFs have also been shown to be involved in tolerance to abiotic stresses, such as heat, cold, and salt. For example, under the condition of dehydration, the expression level of $\operatorname{SmWD40-170~gene~decreased~to~enhance~the~drought~}$ tolerance of Salvia miltiorrhiza by promoting stomatal closure (Liu et al., 2020). Thus, studying the multifunctional $D / W D 4 O \mathrm{TF}$ family from $D$. longan might be of great importance for both increasing the flavonoid accumulation and enhancing their tolerance to abiotic stresses.

In this study, a total of 45 D/WD 40 genes were found from RNA-Seq data based on $\mathrm{Nr}$ annotation, and their identities were further confirmed using SMART and NCBI CD search tools. An unrooted phylogenetic tree was constructed to analyse the evolutionary relationships of DIWD40 proteins from D. longan. Based on the classification strategy followed in the rice and Arabidopsis (Ouyang et al., 2012), 45 DlWD 40 proteins, together with WD40 proteins from Arabidopsis thaliana (monocot) and Zea mays (dicot), were divided into six groups. Among these, two WD40 proteins from Arabidopsis, TTG1 and WDR5a, attracted our attention due to their involvement in flavonoid biosynthesis. The Arabidopsis TTG1 can promote anthocyanin synthesis by positively regulating the expression of DFR and other genes. Petunia AN11 and Fragaria ananassa TTG1, homologous to Arabidopsis TTG1, have also been reported to be involved in the biosynthesis of anthocyanin (Xu et al., 2014). Petunia AN11 can increase anthocyanin accumulation by enhancing the expression of the $D F R$ gene (de Vetten et al., 1997). By contrast, the way in which $F$. ananassa TTG1 increases anthocyanin accumulation is different. $F$. ananassa TTG1 increases anthocyanin accumulation by regulating the $B A N$ gene (Schaart et al., 2013). However, none of the DIWD40 genes identified from the D. longan RNA-Seq data were homologous to the Arabidopsis TTG1. Fortunately, we found a gene (accession NO. Dlo_032775.1) highly homologous to Arabidopsis TTG1 in the D. longan genome. The reasons why the homologous gene was found in the $D$. longan genome rather than transcriptome is likely because it is expressed neither in roots nor in leaves under normal growth environment. However, we could not exclude that its expression might be induced by other factors. For example, the expression of the Arabidopsis TTG1 gene could be induced by abscisic acid (ABA), thereby increasing anthocyanin accumulation (Chen et al., 2020). The Arabidopsis WDR5a gene has been shown to be involved in tolerance to drought stress. Under drought stress, the WDR5a gene is overexpressed, promoting the accumulation of nitric oxide in roots (Liu et al., 2018). Studies have indicated that the massive accumulation of flavonoids in maize and Arabidopsis was a consequence of the increased nitric oxide (Mongin et al., 2012; Tossi et al., 2011). According to the results shown in the phylogenetic tree, the DIWD40-4 gene was highly homologous to the Arabidopsis WDR5a gene. Consequently, it is inferred that the DIWD40-4 gene might function as a WDR5a gene, participating in tolerance to drought stress and flavonoid accumulation.

Diverse cis-elements were found in the promoter regions of 45 D/WD 40 genes using PlantCARE. Some of the cis-elements were associated with stress responses, suggesting that the DIWD40 TF family from $D$. longan might be involved in tolerance to inhospitable growth conditions. Also, the MeJA-responsiveness element was found in many of the $D / W D 40$ genes, and its functions have been explored in diverse plant species. For example, MeJA could increase anthocyanin accumulation in apple through enhancing the expression levels of related genes; all these related genes were proved to contain MeJA response elements (Yan et al., 2020). Therefore, the D/WD 40 genes that contain the MeJA-responsiveness element in promoters could be expected to associate with anthocyanin biosynthesis under MeJA induction. In addition, the cis-element of MYB binding site involved in flavonoid was found in the promoters of both D/WD40-24 and DIWD40-38, which suggest that the expression of these two genes might be triggered by MYB TFs and then participate in the flavonoid biosynthesis in $D$. longan.

miRNAs were also believed to be pivotal factors influencing plant growth and metabolism through posttranscriptional regulation (Wang et al., 2017). A total of 25 D/WD 40 genes were predicted to be targeted by 41 miRNAs using the psRNATarget. Previous studies have shown that the miR3627 is involved in 
anthocyanin biosynthesis in Vitis vinifera L. (Sunitha et al., 2019) Accordingly, we speculate that the D/WD40-33 gene is targeted by miR3627 and might be related to anthocyanin biosynthesis.

The expression patterns of $45 \mathrm{D} / \mathrm{WD} 40$ genes were evaluated by RNA-Seq and qRT-PCR, ten members of which were shown to have different expression levels between root and leaf tissues of $D$. longan. Gene expressions were believed to have close relationships with secondary metabolite accumulations. For example, the high expressions of $A c M Y B 123$ or $A c b H L H 42$ transcription factor genes in Actinidia inner pericarp were proved to contribute to anthocyanin synthesis (Wang et al., 2019). As a result, the DIWD40-20 gene that was highly expressed in leaves was regarded as a candidate gene for further investigation of its involvement in secondary metabolite biosynthesis. One of our future work will focus on the function of DIWD40-20 gene participating in the accumulation of secondary metabolites by using transgenic technology. Also, these ten tissue-specific $D / W D 40$ genes were shown to respond to a $38^{\circ} \mathrm{C}$ heat stress, whereas they showed diverse expression levels in both roots and leaves. The TAWD gene, a member of the WD 40 gene family from Arabidopsis, was found to help resist high temperatures (Hu et al., 2018). Therefore, we speculate that $D / W D 40$ genes with strong thermal responses, including D/WD40-4,D/WD40-20,D/WD40-25, and DIWD40-31, deserve further investigation for their putative functions in resisting heat stress.

\section{Conclusions}

In this study, bioinformatics tools were used to analyse $45 \mathrm{D} / \mathrm{WD} 40$ genes identified from $D$. longan, including physical and chemical properties, conserved domains, cis-acting elements, protein-protein interactions, evolutionary relationships, GO annotations, and miRNA targets. Moreover, the expression pattern of $D / W D 40$ genes in roots and leaves, as well as the responses to heat stress $\left(38^{\circ} \mathrm{C}\right)$, were analysed by qRT-PCR. Ten of the 45 DIWD 40 genes (DIWD40-4, DIWD40-20, DIWD40-21, DIWD40-25, D/WD4031, DIWD40-13, D/WD40-22, DIWD40-32, D/WD40-36, and D/WD40-38) were differentially expressed in roots and leaves. Of these, the DIWD40-20 gene in leaves was nearly 15-fold higher than that in roots. All of these ten $D / W D 40$ genes could respond to heat stress $\left(38^{\circ} \mathrm{C}\right)$. The D/WD40-4, D/WD40-20, D/WD4025 , and DIWD40-31 genes responded most strongly to heat stress. The data reported here expand our understanding of WD40 TFs and provide gene resources for increasing the content of flavonoid through genetic engineering. Also, our findings will provide a basis for improving abiotic stress resistance in plants using transgenic technologies.

\section{Authors' Contributions}

ZW and ZZW conceived and designed the study, as well as wrote the manuscript. ZZW performed the experiments. YXF reviewed and edited the manuscript. XTT, CN and LWL analyzed the data. All authors read and approved the final manuscript.

\section{Acknowledgements}

This study was funded by the Young Scholars with Creative Talents at Harbin University of Commerce (2019CX39), and Doctoral Science Foundation (14LG06). 


\section{Conflict of Interests}

The authors declare that there are no conflicts of interest related to this article.

\section{References}

An XH, Tian Y, Chen KQ, Wang XF, Hao YJ (2012). The apple WD40 protein MdTTG1 interacts with bHLH but not MYB proteins to regulate anthocyanin accumulation. Journal of Plant Physiology 169(7):710-717. https://doi.org/10.1016/j.jplph.2012.01.015

Chen C, Chen H, Zhang Y, Thomas HR, Frank MH, He Y, Xia R (2020). TBtools - an integrative toolkit developed for interactive analyses of big biological data. Molecular Plant S1674-2052(20):30187-30188. https://doi.org/10.1016/j.molp.2020.06.009

Chen JJ, Mei S, Hu YR (2020). 脱落酸激素诱导拟南芥幼苗中花青素的合成 [Abscisic acid induces anthocyanin synthesis in Arabidopsis seedlings]. Guihaia 40(08):1169-1180.

de Vetten N, Quattrocchio F, Mol J, Koes R (1997). The an 11 locus controlling flower pigmentation in petunia encodes a novel WD-repeat protein conserved in yeast, plants, and animals. Genes \& Development 11(11):1422-1434. https://doi.org/10.1101/gad.11.11.1422

Feyissa BA, Arshad M, Gruber MY, Kohalmi SE, Hannoufa A (2019). The interplay between miR156/SPL13 and DFR/WD40-1 regulate drought tolerance in alfalfa. BMC Plant Biology 19(1):434. https://doi.org/10.1186/s12870-019-2059-5

Fonseca S, Rubio V (2019). Arabidopsis CRL4 complexes: surveying chromatin states and gene expression. Frontiers in Plant Science https://doi.org/10.3389/fpls.2019.01095

Higa LA, Zhang H (2007). Stealing the spotlight: CUL4-DDB1 ubiquitin ligase docks WD40-repeat proteins to destroy. Cell Division 2:5. https://doi.org/10.1186/1747-1028-2-5

Ho SC, Hwang LS, Shen YJ, Lin CC (2007). Suppressive effect of a proanthocyanidin-rich extract from longan (Dimocarpus longan Lour.) flowers on nitric oxide production in LPS-stimulated macrophage cells. Journal of Agricultural and Food Chemistry 55(26):10664-10670. https://doi.org/10.1021/jf0721186

Hu R, Xiao J, Gu T, Yu X, Zhang Y, Chang J, Yang G, He G (2018a). Genome-wide identification and analysis of WD40 proteins in wheat (Triticum aestivum L.). BMC Genomics 19(1):803. https://doi.org/10.1186/s12864-0185157-0

$\mathrm{Hu}$ Z, Zhao L, Hu Z, Wang K (2018b). Hierarchical structure, gelatinization, and digestion characteristics of starch from longan (Dimocarpus longan Lour.) seeds. Molecules 23(12):3262. https://doi.org/10.3390/molecules23123262

Huang F, Liu H, Zhang R, Dong L, Liu L, Ma Y, ... Zhang M (2019). Physicochemical properties and prebiotic activities of polysaccharides from longan pulp based on different extraction techniques. Carbohydrate Polymers 206:344351. https://doi.org/10.1016/j.carbpol.2018.11.012

Jaakola L, Pirttilä AM, Halonen M, Hohtola A (2001). Isolation of high-quality RNA from bilberry (Vaccinium myrtillus L.) fruit. Molecular Biotechnology 19(2):201-203. https://doi.org/10.1385/MB:19:2:201

Jue D, Sang X, Liu L, Shu B, Wang Y, Liu C, Xie J, Shi S (2018). Identification of WRKYgene family from Dimocarpus longan and its expression analysis during flower induction and abiotic stress responses. International Journal of Molecular Sciences 19(8):2169. https://doi.org/10.3390/ijms19082169

Kong D, Li M, Dong Z, Ji H, Li X (2015). Identification of TaWD40D, a wheat WD40 repeat-containing protein that is associated with plant tolerance to abiotic stresses. Plant Cell Reports 34(3):395-410. https://doi.org/10.1007/s00299-014-1717-1

Li Q, Zhao P, Li J, Zhang C, Wang L, Ren Z (2014). Genome-wide analysis of the WD-repeat protein family in cucumber and Arabidopsis. Molecular Genetics and Genomics 289(1):103-124. https://doi.org/10.1007/s00438-0130789-X

Li WH, Yang J, Gu X (2005). Expression divergence between duplicate genes. Trends in Genetics 21(11):602-607. https://doi.org/10.1016/j.tig.2005.08.006 
Lin Y, Lai Z (2013). Comparative analysis reveals dynamic changes in miRNAs and their targets and expression during somatic embryogenesis in longan (Dimocarpus longan Lour.). PloS One 8(4):e60337. https://doi.org/10.1371/journal.pone.0060337

Liu WC, Zheng SQ, Yu ZD, Gao X, Shen R, Lu YT (2018). WD40-REPEAT 5a represses root meristem growth by suppressing auxin synthesis through changes of nitric oxide accumulation in Arabidopsis. The Plant Journal 93(5):883-893. https://doi.org/10.1111/tpj.13816

Liu XF, Feng C, Zhang MM, Yin XR, Xu CJ, Chen KS (2013). The MrWD40-1 gene of Chinese bayberry (Myrica rubra) interacts with MYB and bHLH to enhance anthocyanin accumulation. Plant Molecular Biology Reporter 31(6):1474-1484. Https://doi.org/10.1007/s11105-013-0621-0

Liu YC, Ma W, Niu JF, Li B, Zhou W, Liu S, ... Wang ZZ (2020). Systematic analysis of SmWD40s, and responding of SmWD40-170 to drought stress by regulation of ABA- and $\mathrm{H}_{2} \mathrm{O}_{2}$-induced stomal movement in Salvia miltiorrhiza bunge. Plant Physiology and Biochemistry 153:131-140. https://doi.org/10.1016/j.plaphy.2020.05.017

Ma J, An K, Zhou JB, Wu NS, Wang Y, Ye ZQ, Wu YD (2019). WDSPdb: an updated resource for WD40 proteins. Bioinformatics 35(22):4824-4826. https://doi.org/10.1093/bioinformatics/btz460

Mongin AA, Dohare P, Jourd'heuil D (2012). Selective vulnerability of synaptic signaling and metabolism to nitrosative stress. Antioxidants \& Redox Signalling 17(7):992-1012. https://doi.org/10.1089/ars.2012.4559

Nash P, Tang X, Orlicky S, Chen Q, Gertler FB, Mendenhall MD, ... Tyers M (2001). Multisite phosphorylation of a CDK inhibitor sets a threshold for the onset of DNA replication. Nature 414(6863):514-521. https://doi.org/10.1038/35107009

Ouyang Y, Huang X, Lu Z, Yao J (2012). Genomic survey, expression profile and co-expression network analysis of Os WD40 family in rice. BMC Genomics 13:100. https://doi.org/10.1186/1471-2164-13-100

Qin L, Sun L, Wei L, Yuan J, Kong F, Zhang Y, ... Liu S (2020). Maize SRO1e represses anthocyanin synthesis through regulating the MBW complex in response to abiotic stress. The Plant Journal https://doi.org/10.1111/tpj.15083

Schaart JG, Dubos C, Romero De La Fuente I, van Houwelingen AM, de Vos RC, Jonker HH, ... Bovy AG (2013). Identification and characterization of MYB-bHLH-WD40 regulatory complexes controlling proanthocyanidin biosynthesis in strawberry (Fragaria $\times$ ananassa) fruits. New Phytologist 197(2):454-467. https://doi.org/10.1111/nph.12017

Schmittgen TD, Livak KJ (2008). Analyzing real-time PCR data by the comparative C(T) method. Nature Protocols 3(6):1101-1108. https://doi.org/10.1038/nprot.2008.73

Sunitha S, Loyola R, Alcalde JA, Arce-Johnson P, Matus JT, Rock CD (2019). The role of UV-B light on small RNA activity during grapevine berry development. G3: Genes, Genomes, Genetics 9(3):769-787. https://doi.org/10.1534/g3.118.200805

Tao N, Zhu W, Gan M, Chen M, Li T, Tendu A... Yang Q (2019). Genome-wide identification and functional analysis of the WDR protein family in potato. 3 Biotech 9(11):432. https://doi.org/10.1007/s13205-019-1965-4

Tossi V, Amenta M, Lamattina L, Cassia R (2011). Nitric oxide enhances plant ultraviolet-B protection up-regulating gene expression of the phenylpropanoid biosynthetic pathway. Plant, Cell \& Environment 34(6):909-921. https://doi.org/10.1111/j.1365-3040.2011.02289.x

van Nocker S, Ludwig P (2003). The WD-repeat protein superfamily in Arabidopsis: conservation and divergence in structure and function. BMC Genomics 4(1):50. https://doi.org/10.1186/1471-2164-4-50

Wang B, Tan HW, Fang W, Meinhardt LW, Mischke S, Matsumoto T, Zhang D (2015). Developing single nucleotide polymorphism (SNP) markers from transcriptome sequences for identification of longan (Dimocarpus longan) germplasm. Horticulture Research 2:14065. https://doi.org/10.1038/hortres.2014.65

Wang L, Tang W, Hu Y, Zhang Y, Sun J, Guo X, ... Liu Y (2019). A MYB/bHLH complex regulates tissue-specific anthocyanin biosynthesis in the inner pericarp of red-centered kiwifruit Actinidia chinensis cv. Hongyang. The Plant Journal 99(2):359-378. https://doi.org/10.1111/tpj.14330

Wang M, Gao Y, Qu P, Qing S, Qiao F, Zhang Y, Mager J, Wang Y (2017). Sperm-borne miR-449b influences cleavage, epigenetic reprogramming and apoptosis of SCNT embryos in bovine. Scientific Reports 7(1):13403. https://doi.org/10.1038/s41598-017-13899-8

Wu H, Lv H, Li L, Liu J, Mu S, Li X, Gao J (2015). Genome-wide analysis of the AP2/ERF Transcription factors family and the expression patterns of DREB genes in moso bamboo (Phyllostachys edulis). PloS One 10(5):e0126657. https://doi.org/10.1371/journal.pone.0126657 
Xia KW (2019). 拟南芥WD40家族蛋白TAWD在抵御高温胁迫中的功能研究 [Function study of the WD40repeat protein TAWD in Arabidopsis thermotolerance]. Central China Normal University.

Xu W, Grain D, Bobet S, Le Gourrierec J, Thévenin J, Kelemen Z, Lepiniec L, Dubos C (2014). Complexity and robustness of the flavonoid transcriptional regulatory network revealed by comprehensive analyses of MYBbHLH-WDR complexes and their targets in Arabidopsis seed. New phytologist 202(1):132-144. https://doi.org/10.1111/nph.12620

Xue Y, Wang W, Liu Y, Zhan R, Chen Y (2015). Two new flavonols glycosides from Dimocarpus longan leaves. Natural Product Research 29(2):163-168. https://doi.org/10.1080/14786419.2014.971318

Yan J, He L, Xu S, Wan Y, Wang H, Wang Y, Yu L, Zhu W (2020). Expression analysis, functional marker development and verification of AgFNSI in celery. Scientific Reports 10(1):531. https://doi.org/10.1038/s41598-019$57054-X$

Yuan F, Leng B, Zhang H, Wang X, Han G, Wang B (2019). A WD40-repeat protein from the recretohalophyte Limonium bicolor enhances trichome formation and salt tolerance in Arabidopsis. Frontiers in Plant Science 10:1456. https://doi.org/10.3389/fpls.2019.01456

Zheng W, Xie, TT, Yu XF, Ning C, Zhang ZW (2020). Characterization of bZIPtranscription factors from Dimocarpus longan Lour. and analysis of their tissue-specific expression patterns and response to heat stress. Journal of Genetics 99:69. https://doi.org/10.1007/s12041-020-01229-3

OPEN ACCESS

(C)

The journal offers free, immediate, and unrestricted access to peer-reviewed research and scholarly work. Users are allowed to read, download, copy, distribute, print, search, or link to the full texts of the articles, or use them for any other lawful purpose, without asking prior permission from the publisher or the author.

License - Articles published in Notulae Botanicae Horti Agrobotanici Cluj-Napoca are Open-Access, distributed under the terms and conditions of the Creative Commons Attribution (CC BY 4.0) License. (C) Articles by the authors; UASVM, Cluj-Napoca, Romania. The journal allows the author(s) to hold the copyright/to retain publishing rights without restriction. 